\title{
The effect of sodium on the Pd-catalyzed reduction of NO by methane
}

\author{
I.V. Yentekakis ${ }^{\mathrm{a},{ }^{*}}$, R.M. Lambert ${ }^{\mathrm{b}}$, M. Konsolakis ${ }^{\mathrm{a}}$, V. Kiousis ${ }^{\mathrm{a}}$ \\ ${ }^{a}$ Department of Chemical Engineering, University of Patras and ICEHT/FORTH, Patras GR-26500, Greece \\ ${ }^{\mathrm{b}}$ Department of Chemistry, University of Cambridge, Cambridge CB2 $1 \mathrm{EW}, \mathrm{UK}$
}

Received 15 March 1998; received in revised form 13 May 1998; accepted 17 May 1998

\begin{abstract}
The kinetics of NO reduction by methane over Pd catalysts supported on $8 \mathrm{~mol} \%$ yttria-stabilised zirconia (YSZ) has been studied at atmospheric pressure in the 620-770 K temperature range. Langmuir-Hinshelwood type kinetics are found with characteristic rate maxima reflecting competitive adsorption of $\mathrm{NO}$ and methane: $\mathrm{NO}$ adsorption is much more pronounced than that of methane within the temperature range of this investigation. $\mathrm{Pd}$ is an effective catalyst: $100 \%$ selectivity towards $\mathrm{N}_{2}$ can be achieved at $100 \%$ conversion of $\mathrm{NO}$ over this wide temperature range. Sodium causes strong poisoning of the reaction. The response of the system to variations in NO and methane concentrations, temperature, and sodium loading indicate that this is due to the Na-induced enhancement of NO chemisorption and dissociation relative to methane adsorption, i.e. sodium enhances oxygen poisoning of the catalyst. These results stand in revealing contrast to the strong promotional effect of sodium in the reduction of NO by propene over the same catalysts. The very different response of the two hydrocarbon reductants to Na doping of the Pd catalyst receives a consistent explanation. (C) 1998 Elsevier Science B.V. All rights reserved.
\end{abstract}

Keywords: Sodium; NO reduction; Methane; Palladium; YSZ

\section{Introduction}

The catalytic reduction of $\mathrm{NO}_{x}$ emissions produced by both stationary and automotive combustion processes is of major environmental importance [1,2]. Automotive exhaust catalytic converters - the socalled three-way catalysts (TWC) - employ a wellestablished technology in controlling $\mathrm{NO}_{x}, \mathrm{CO}$ and hydrocarbon emissions, based variously on the catalytic properties of $\mathrm{Pt}, \mathrm{Pd}$ and $\mathrm{Rh}$ metals. Selective reduction with ammonia is the most commonly used technology for controlling NO emissions from sta-

\footnotetext{
*Corresponding author. Fax: +30 61 993255; e-mail: yyentek@iceht.forth.gr
}

tionary sources. Recently, however, there has been strong interest in pursuing alternative approaches to abate nitrogen oxides emissions from both mobile and stationary sources. There are drawbacks with using $\mathrm{NH}_{3}$ so that the utilization of hydrocarbons rather than ammonia for the reduction of $\mathrm{NO}_{x}$ is a subject of intensive research [2].

Methane would be a convenient and inexpensive reductant for NO. Moreover, it is the principal alkane component (up to $20 \%$ ) in lean burn exhaust gases and in the emissions from natural gas-powered vehicles. Because of the potential technological importance of the simultaneous removal of $\mathrm{NO}$ and methane, the $\mathrm{NO}+\mathrm{CH}_{4}$ reaction in the absence or in the presence of oxygen has attracted much recent research. Over 100 
papers dealing with this subject have appeared since 1997, and most efforts have concentrated on three classes of catalytic materials, as follows.

(i) Ion-exchanged zeolite catalysts: Iwamoto et al. [3-5], Hamada et al. [6] and Almor et al. [7-9], showed that metal ion-exchanged zeolite catalysts can be active for either the direct decomposition of NO [3] or the selective reduction of $\mathrm{NO}$ by hydrocarbons [4-13]. Propene, propane, ethylene and methane have been successfully employed as reductants. Formulations such as H-ZSM5 [6,11], Co-ZSM5 [7,9,10], Pd/H-, Na-ZSM5 [11], CuZSM5 [3,10] Rh-ZSM5 [10], Pt-ZSM5 [10], MnZSM5 [9,13], Ni-ZSM5 [9], Pt-dealuminated Y zeolite (Pt-DeY) [12], metal-exchanged mordenite [9] or metal-exchanged ferrierites [8], have been extensively studied.

(ii) Rare earth oxides: Vannice et al. [14-16] found that these materials, which are active for the oxidative coupling of methane, can be active catalysts for the reduction of $\mathrm{NO}$ by methane in the absence or in the presence of oxygen. $\mathrm{La}_{2} \mathrm{O}_{3}$ and $\mathrm{Sm}_{2} \mathrm{O}_{3}$ with and without $\mathrm{Sr}$ doping were the most active catalysts in this class, with specific activities comparable to that of Co-ZSM5 $[15,16]$. (iii) Platinum group metals: One might expect these metals to be effective catalysts for the $\mathrm{NO}+\mathrm{CH}_{4}$ reaction, but there is very little information in the literature. Subramanian et al. [17] reported high conversion efficiencies for Pd-based catalysts, and recent systematic studies of silica or alumina supported $\mathrm{Pd}, \mathrm{Pt}$ and $\mathrm{Rh}$ catalysts have been reported by Burch et al. [18,19]. Measurements were made both in the absence and in the presence of oxygen. Burch et al. concluded that $\mathrm{Pt}$ is effective for the removal of both reactants, although it may be difficult to optimize the simultaneous conversion of both under the same conditions. They also observed an influence of the support on the activity of all three metals, the effect being most pronounced in the case of $\mathrm{Pd}$ [18].

Electrochemical promotion (EP) [20] provides an alternative approach to the improvement of catalyst performance in $\mathrm{NO}_{x}$ reduction. We used EP to investigate the effect of $\mathrm{Na}$ as a promoter for the Ptcatalysed NO reduction by propene $[21,22]$. It was shown that $\mathrm{Na}$ supplied electrochemically from a $\beta^{\prime \prime}$-alumina solid electrolyte (a $\mathrm{Na}^{+}$conductor) to a Pt film interfaced with this electrolyte strongly promotes the reaction. In effect $\mathrm{Pt}$ could be induced to behave like Rh. Significant enhancement in $\mathrm{N}_{2} / \mathrm{N}_{2} \mathrm{O}$ selectivity were also achieved. The promotional effects of $\mathrm{Na}$ was found to be significant both in the absence [21] or in the presence [22] of oxygen, a result of some technological significance.

Most recently [23], guided by these EP studies, we investigated Na-induced promotion of NO reduction by propene over conventional dispersed Pd catalysts supported on $8 \mathrm{~mol} \%$ yttria stabilised zirconia (YSZ). (Development and application of Pd-based catalysts currently attracts much attention [24]). The choice of support (YSZ) was influenced by recent studies which show that YSZ maximises the turnover activity of Pd for reactions relevant to TWC chemistry [25]. The behaviour of these catalysts closely paralleled that of their EP analogues: very large activity enhancement and significant increases in $\mathrm{N}_{2}$ selectivity (from 75 to $>95 \%$ ) were achieved [23]. The results were understandable in terms of Na-induced increases in the strength of NO chemisorption relative to propene, accompanied by weakening of the $\mathrm{N}-\mathrm{O}$ bond [23]. The latter facilitates NO dissociation, which is thought to be the crucial reaction initiating step.

Here, we report the kinetic behaviour of the $\mathrm{NO}+\mathrm{CH}_{4}$ reaction over Pd supported on YSZ. The effect of sodium addition on activity and selectivity is also investigated in detail. Again, the results parallel those obtained for the $\mathrm{NO}+\mathrm{CH}_{4}$ reaction catalysed by a Pt metal film electro-pumped with Na supplied from $\mathrm{Na} \beta^{\prime \prime}$ alumina [26] where it is clear that the observed effects are due to Na-induced changes in the surface chemistry of the platinum metal. The present results stand in interesting contrast with those found for NO reduction by $\mathrm{C}_{3} \mathrm{H}_{6}$ [23]. A consistent explanation of the effects of Na promotion is proposed. This sheds light on the observed differences in behaviour of alkanes and alkenes during NO reduction on noble metals.

\section{Experimental methods}

\subsection{Materials and apparatus}

The preparation and characterisation of the samples has been described elsewhere [23]. In brief, the Pd 
Table 1

Properties of the $0.5 \mathrm{wt} \% \mathrm{Pd} / \mathrm{YSZ}$ catalysts ${ }^{\mathrm{a}}$

\begin{tabular}{lllllll}
\hline $\begin{array}{l}\text { Catalyst } \\
\text { code }\end{array}$ & $\begin{array}{l}\text { Na-loading } \\
(\mathrm{wt} \%)\end{array}$ & $\begin{array}{l}\text { Nominal Na } \\
\text { coverage }^{\mathrm{b}}(\%)\end{array}$ & $\begin{array}{l}\mathrm{Pd} / \mathrm{Na} \\
(\text { atom/atom })\end{array}$ & $\begin{array}{l}\mathrm{H}_{2} \text { uptake } \\
\left(\mathrm{cm}^{3} \mathrm{STP} / \mathrm{g}\right)\end{array}$ & $\begin{array}{l}\text { Dispersion } \\
(\%)\end{array}$ & $\begin{array}{l}\text { Active metal surface } \\
\operatorname{area}^{\mathrm{c}}\left(\mathrm{m}^{2} / \mathrm{g}\right)\end{array}$ \\
\hline $\mathrm{C} 1$ & 0 & 0 & $\infty / 1$ & 0.106 & 20 & 0.45 \\
$\mathrm{C} 2$ & 0.017 & 5 & $6 / 1$ & 0.105 & 20 & 0.44 \\
$\mathrm{C} 3$ & 0.034 & 10 & $3 / 1$ & 0.131 & 25 & 0.55 \\
$\mathrm{C} 4$ & 0.068 & 20 & $1.5 / 1$ & 0.123 & 24 & 0.52 \\
$\mathrm{C} 5$ & 0.102 & 30 & $1 / 1$ & 0.127 & 24 & 0.54 \\
\hline
\end{tabular}

${ }^{a}$ All the above surface characterization measurements refer to used catalysts.

${ }^{\mathrm{b}}$ Based on the assumption that all $\mathrm{Na}$ is present at the surface and distributed uniformly over the entire available area (Pd+YSZ), without any incorporation into the bulk.

${ }^{\mathrm{c}}$ Calculations based on a Pd surface atom density of $1.27 \times 10^{19}$ atoms $/ \mathrm{m}^{2}$.

catalysts were prepared by incipient wetness impregnation of the YSZ support (Zirconia Sales) using a $\mathrm{pH}=3$ solution of $\mathrm{PdCl}_{2}$ (Alfa products) of appropriate concentration so as to yield $0.5 \mathrm{wt} \% \mathrm{Pd}$ metal loading. Subsequent impregnation with $\mathrm{NaNO}_{3}$ was used to produced catalysts with a range of Na loadings. The suspension was dried in a rotary evaporator at $353 \mathrm{~K}$ and the impregnated supports were dried overnight at $383 \mathrm{~K}$. The resulting precursors were heated in flowing $\mathrm{He}(1 \mathrm{~h} / 673 \mathrm{~K})$, followed by $\mathrm{H}_{2}$ reduction $(673 \mathrm{~K} /$ $\left.1 \mathrm{~h} / 100 \mathrm{~cm}^{3} \mathrm{~min}^{-1}\right)$. Metal dispersion was measured by $\mathrm{H}_{2}$ chemisorption at $333 \mathrm{~K}$ and the BET surface area of the YSZ support was measured by $\mathrm{N}_{2}$ adsorption at $77 \mathrm{~K}$ and found to be $\sim 7 \mathrm{~m}^{2} \mathrm{~g}^{-1}$. The data are summarised in Table 1: it is important to note that the presence of varying amounts of $\mathrm{Na}$ does not significantly affect the catalyst dispersion.

For purposes of convenient comparison, a nominal percentage surface coverage by $\mathrm{Na}$ has been calculated for each of the catalysts $\mathrm{C} 2-\mathrm{C} 5$ based on the assumption that all the promoter is present at the surface and distributed uniformly over the entire available area $(\mathrm{Pd}+\mathrm{YSZ})$, without any incorporation into the bulk. In fact, our electron spectroscopic data (Auger and XPS [23]) showed that coverage of the catalyst by $\mathrm{Na}$ increases monotonically with promoter loading and that there is no tendency towards promoter agglomeration at the higher loadings. Although, a very small but constant tendency to accumulate subsurface or dissolved $\mathrm{Na}$ as the promoter loading is increased above 5\% nominal Na coverage was observed.

Our XPS measurements [23] also demonstrated that use of $\mathrm{PdCl}_{2}$ did not result in significant chlorine contamination of the catalysts. Moreover, control experiments carried out with catalysts prepared by a chlorine-free route $\left[\mathrm{Pd}\left(\mathrm{NO}_{3}\right)_{2}\right]$ confirmed the absence of any influence due to residual chlorine on the performance catalysts C1-C5 [23].

Reactants were Air Liquide certified standards of $8 \% \mathrm{NO}$ in $\mathrm{He}$ and $20 \%$ methane in He. These were further diluted in ultrapure $\mathrm{He}(99.999 \%)$ and supplied to the reactor at 1 bar. Catalyst testing was performed in a fixed bed, single pass, plug flow reactor, consisting of a 0.4-cm ID quartz tube. The total gas-flow rate was high, typically $100-600 \mathrm{~cm}^{3} \mathrm{~min}^{-1}$, in order to minimize conversion of reactants and to eliminate massand heat-transfer effects during acquisition of the kinetic data. The absence of intraparticle and interparticle diffusional effects was experimentally confirmed by variation of catalyst particle size and gasflow rate. $\mathrm{NO}$ and $\mathrm{CH}_{4}$ conversions were always below 25 and $10 \%$, respectively, in experiments where kinetic data were acquired. Catalyst loadings were typically ca. $7.5 \mathrm{mg}$, the sample being diluted further by admixture with $\sim 70 \mathrm{mg} 100-325$ mesh $\alpha-\mathrm{Al}_{2} \mathrm{O}_{3}$ (Alpha products). The analysis of the reactants and products was performed by on-line gas chromatography (SHIMADZU-14B) and on-line IR spectroscopy (Fisher-Rosemount, Binos 100 NDIR $\mathrm{CO}_{2}$ Analyzer). Separation of $\mathrm{N}_{2}, \mathrm{NO}, \mathrm{CH}_{4}$ and $\mathrm{CO}$ was achieved in a molecular-sieve $5 \mathrm{~A}$ column at $353 \mathrm{~K}$ while $\mathrm{CO}_{2}$ and $\mathrm{N}_{2} \mathrm{O}$ were separated using a porapak- $\mathrm{N}$ column at the same temperature. Before measurements were taken, the catalysts were operated for 1 day in air and 5 days in a reactive gas mixture at $723 \mathrm{~K}$ to ensure stable operation. 

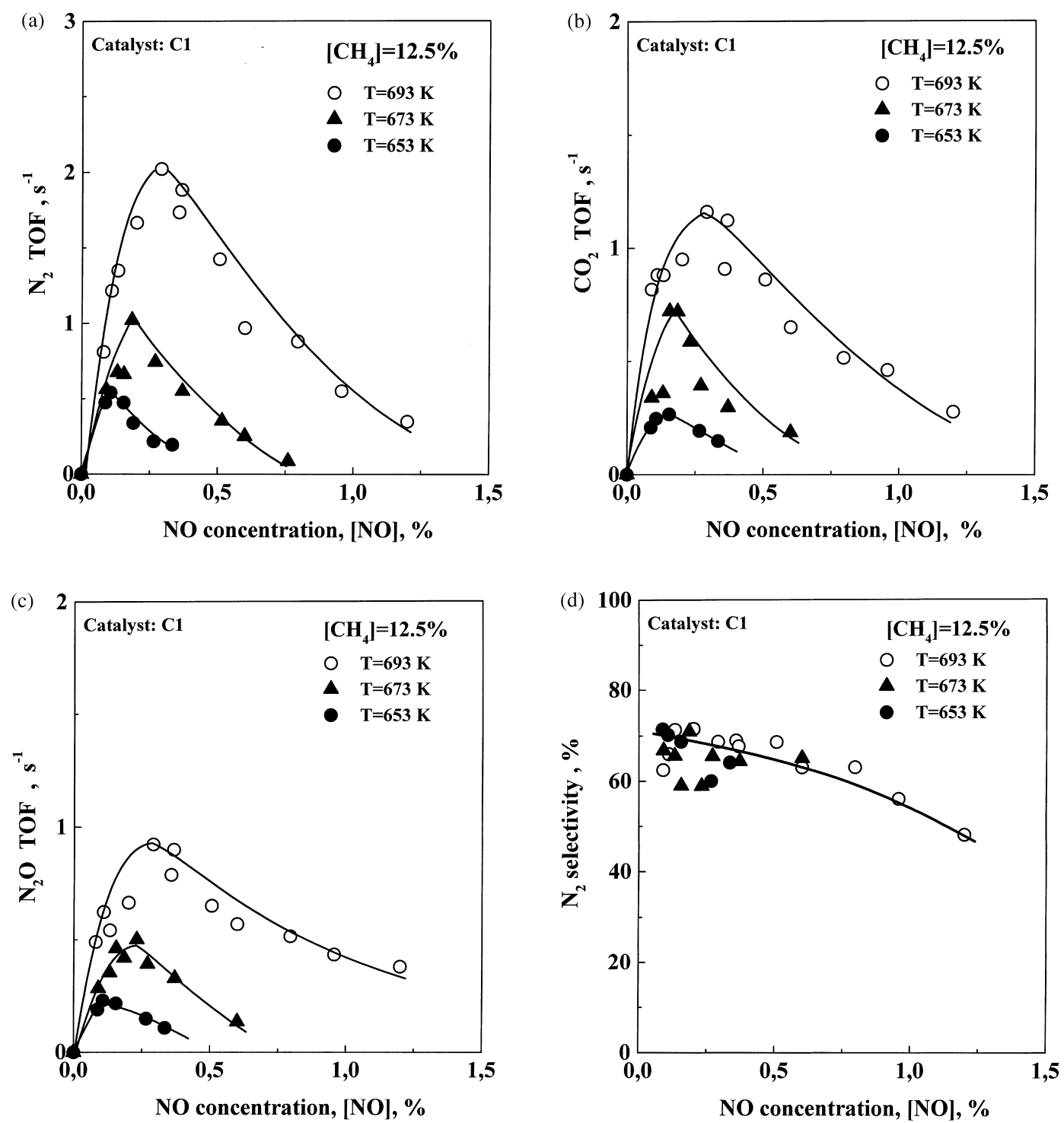

Fig. 1. The effect of $\mathrm{NO}$ concentration on the turnover (TOF) formation rates of (a) $\mathrm{N}_{2}$, (b) $\mathrm{CO}_{2}$, and (c) $\mathrm{N}_{2} \mathrm{O}$ and for (d) $\mathrm{N}_{2}$ selectivity, at three different temperatures and fixed methane concentration in the gas phase $\left[\mathrm{CH}_{4}\right]=12.5 \%$; concentrations refer to outlet reactor conditions; catalyst $\mathrm{C} 1$ (Na-free catalyst).

\section{Results}

\subsection{Kinetic measurements}

Fig. 1(a-c) show the kinetics of $\mathrm{N}_{2}, \mathrm{CO}_{2}$ and $\mathrm{N}_{2} \mathrm{O}$ formation for three different temperatures, as a function of NO concentration [NO], for fixed methane concentration $\left(\left[\mathrm{CH}_{4}\right]=12.5 \%\right)$ for the unpromoted
(Na-free) Pd catalyst $\mathrm{C} 1$. As noted above, the conversion of reactants was limited to no more than $10 \%$ $\left(\mathrm{CH}_{4}\right)$ and $25 \%(\mathrm{NO})$ of the initial concentration. Fig. 1(d) shows the corresponding behaviour of the $\mathrm{N}_{2}$ selectivity, $S_{\mathrm{N}_{2}}$, defined as

$S_{\mathrm{N}_{2}}=r_{\mathrm{N}_{2}} /\left(r_{\mathrm{N}_{2}}+r_{\mathrm{N}_{2} \mathrm{O}}\right)$

It is apparent that the system follows Langmuir- 
Hinshelwood type kinetics with characteristic rate maxima reflecting competitive adsorption of NO and methane: the reaction rate declines on either side of an optimum reactant partial pressure ratio, corresponding to the optimum surface coverages of catalytically active species. It is also evident that these maxima occur at very low NO : methane ratios (in general <0.03), indicating weaker adsorption of
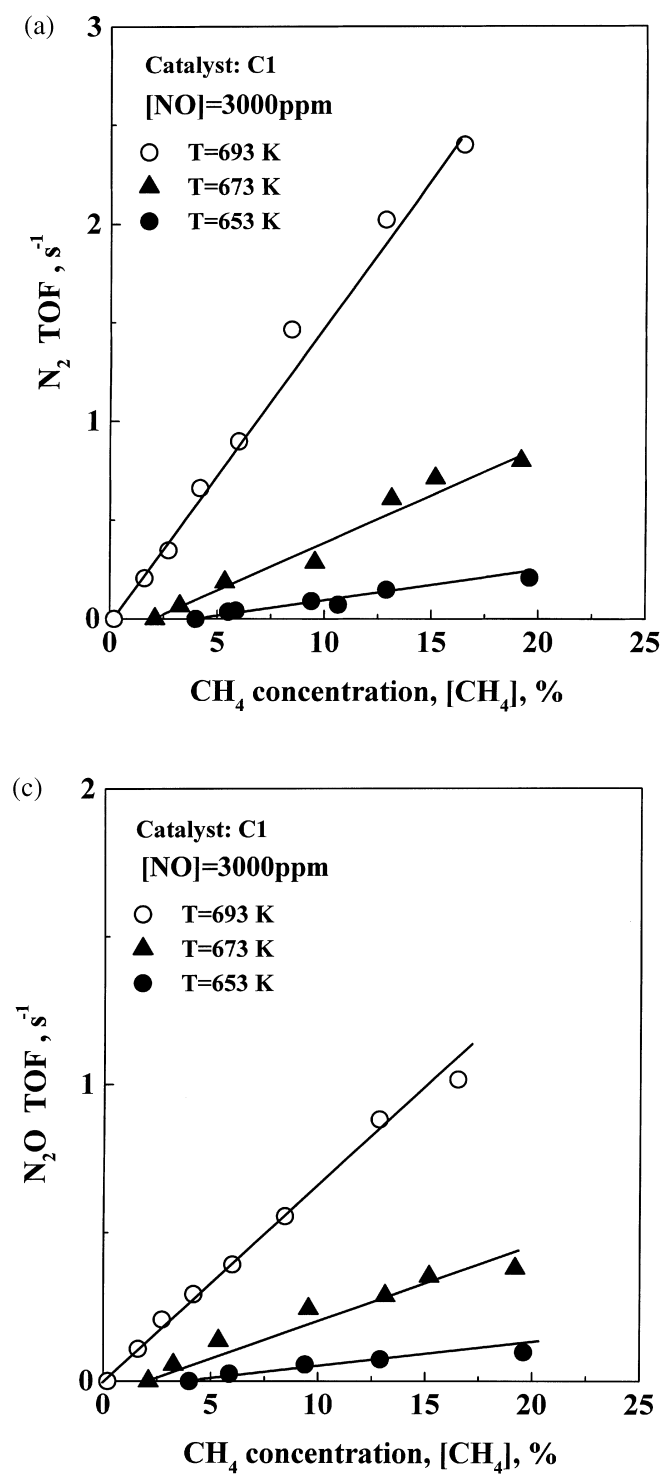

methane on the metal surface relative to NO. The positions of the maxima depend markedly on reaction temperature: there is a systematic shift to lower $[\mathrm{NO}]:\left[\mathrm{CH}_{4}\right]$ ratios with decreasing temperature. Fig. 1(d) shows that there is a monotonic decrease in $\mathrm{N}_{2}$ selectivity as a function of increasing [NO].

Fig. 2(a-d) present analogous results for the dependence of $\mathrm{N}_{2}, \mathrm{CO}_{2}$ and $\mathrm{N}_{2} \mathrm{O}$ turnover rates and $\mathrm{N}_{2}$
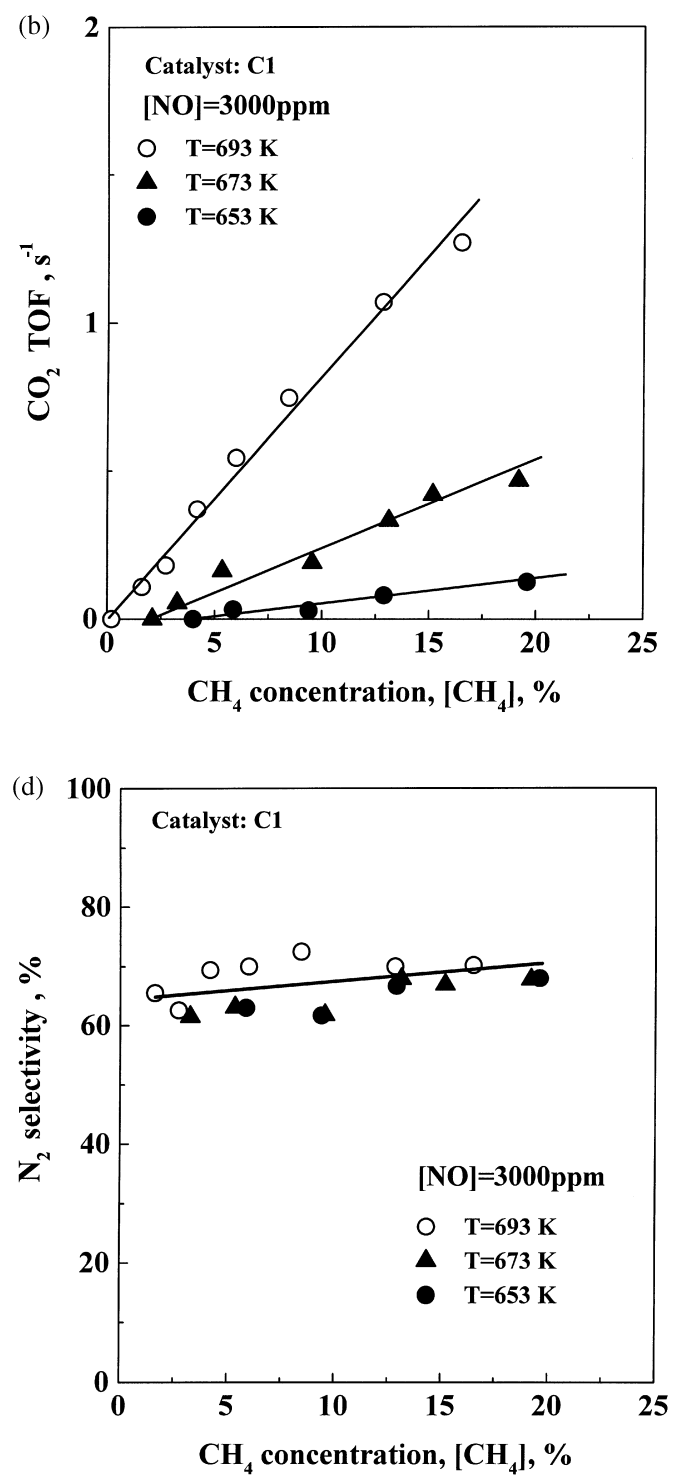

Fig. 2. The effect of $\mathrm{CH}_{4}$ concentration on the TOF rates of (a) $\mathrm{N}_{2}$, (b) $\mathrm{CO}_{2}$, and (c) $\mathrm{N}_{2} \mathrm{O}$ and for (d) $\mathrm{N}_{2}$ selectivity, at three different temperatures and fixed $\mathrm{NO}$ concentration in the gas phase $[\mathrm{NO}]=3000 \mathrm{ppm}$; concentrations refer to outlet reactor conditions; catalyst $\mathrm{C} 1$ (Nafree catalyst). 
selectivity, at three different temperatures, and for fixed $[\mathrm{NO}]=3000 \mathrm{ppm}$, as a function of $\mathrm{CH}_{4}$ concentration, reactant conversion again being limited to the values specified above. In this case, the reaction exhibits first-order dependence on $\left[\mathrm{CH}_{4}\right]$ and no rate maxima are found within the range of accessible experimental conditions. Comparison of the trends shown in Figs. 1 and 2 strongly supports the view that under all conditions used in this study, the adsorption of NO on the catalyst is much stronger than that of methane, i.e. a transition from positive to negative order in NO with increasing NO concentration, and first-order behaviour in $\mathrm{CH}_{4}$ under all conditions. In the present case, the selectivity towards $\mathrm{N}_{2}$ increases slightly with $\left[\mathrm{CH}_{4}\right]$ (Fig. 2(d)).

Closer inspection of Fig. 2(a-c) shows that in the case of the 653 and $673 \mathrm{~K}$ data there is a threshold value of $\left[\mathrm{CH}_{4}\right]$ below which no reaction is detectable. We shall denote this threshold value as $\left[\mathrm{CH}_{4}\right]^{*}$ and its significance is discussed below. In the interests of clarity, in each of Fig. 2(a-c) the observed zero rates at finite methane concentration are shown only once for every set of data. This threshold effect was observed at all methane concentrations with lower values than those illustrated in Fig. 2.

\subsection{Effect of sodium addition}

Fig. 3(a-c) show the effect of increasing sodium addition on the $\mathrm{N}_{2}, \mathrm{CO}_{2}$ and $\mathrm{N}_{2} \mathrm{O}$ rates and on $\mathrm{N}_{2}$ selectivity (Fig. 3(d)), on varying $\left[\mathrm{CH}_{4}\right]$ at fixed temperature and NO concentration. Again, in the interests of clarity, the observed zero rates at finite methane concentration are shown only once for every set of data. Na addition causes a monotonic decrease in the rates: sodium always poisons the reduction of NO by methane. This is strikingly different from the response of the $\mathrm{NO}+$ propene reaction where strong initial promotion by $\mathrm{Na}$ is observed for low to intermediate loadings [23]. In addition to the rate inhibition, it can be seen that $\mathrm{Na}$ exerts a pronounced effect on the value of $\left[\mathrm{CH}_{4}\right]^{*}$ - thought to be the concentration of methane which is necessary to overcome the O-poisoning of the surface, resulting in initiation of the surface reaction. Although, the selectivity of the Na-containing catalysts (C2-C5, Fig. 3(d)) is always systematically below that of the Na-free catalyst (C1), the scatter in the data precludes conclusions being drawn about the dependence of this effect on $\mathrm{Na}$ content.

The effect of $\mathrm{Na}$ addition on activity on varying [NO] at fixed $\left[\mathrm{CH}_{4}\right]=12.5 \%$ is shown in Fig. 4. The strong Na-induced poisoning effect is again clear. It is also apparent that $\mathrm{Na}$ induces a progressive shift in the rate maxima to lower [NO] values. The results for catalysts $\mathrm{C} 3$ and $\mathrm{C} 4$ fit this trend: they have been omitted from the figure for clarity. These results show clearly that $\mathrm{Na}$ enhances the adsorption of $\mathrm{NO}$ relative to that of methane. A comparison of Figs. 1 and 4 shows that $0.017 \mathrm{wt} \%$ of $\mathrm{Na}$ (nominal $\mathrm{Na}$ coverage of $\sim 5 \%$; normalized as discussed above, see also Ref. [23]), reduces the rate by an amount equivalent to a temperature reduction of $\sim 20 \mathrm{~K}$.

\subsection{Effect of temperature}

Arrhenius plots were obtained with catalysts $\mathrm{C} 1-\mathrm{C} 5$ over the $620-720 \mathrm{~K}$ temperature interval. These showed that poisoning by Na occurs over the whole range of temperatures investigated. The apparent activation energies for $\mathrm{N}_{2}, \mathrm{~N}_{2} \mathrm{O}$ and $\mathrm{CO}_{2}$ formation rates were similar $(\sim 160 \mathrm{~kJ} / \mathrm{mol})$ and within experimental error no systematic variation with sodium loading was discernible.

The effect of reaction temperature on conversion was studied for the most active catalyst $(\mathrm{C} 1, \mathrm{Na}-\mathrm{free})$ as a function of $\left[\mathrm{CH}_{4}\right]:[\mathrm{NO}]$ ratio (Fig. 5). The amount of catalyst used was $w=7.5 \mathrm{mg}$ and the total flow rate was $60 \mathrm{~cm}^{3} \mathrm{~min}^{-1}$ (with $[\mathrm{NO}]=2000 \mathrm{ppm}$ ). In terms of the number of available surface Pd atoms, this implies an effective contact time of NO (defined as (surface Pd atoms/NO atoms fed/s)), of the order of $0.8 \mathrm{~s}$. This is a useful parameter which permits straightforward quantitative comparisons to be made with other work. A $100 \%$ NO conversion was achievable for all $\left[\mathrm{CH}_{4}\right]:[\mathrm{NO}]$ ratios (Fig. 5(a)). Note that increase of the $\left[\mathrm{CH}_{4}\right]:[\mathrm{NO}]$ ratio causes a very pronounced decrease in the reaction temperature necessary for complete NO conversion. Fig. 5(b) shows the temperature dependence of $\mathrm{N}_{2} \mathrm{O}$ production for the same three $\left[\mathrm{CH}_{4}\right]$ : [NO] ratios. $\mathrm{N}_{2} \mathrm{O}$ formation initially increases with temperature, passes through a maximum located in the region of the catalyst light-off temperature, then, it decreases abruptly, so that at 
(a)

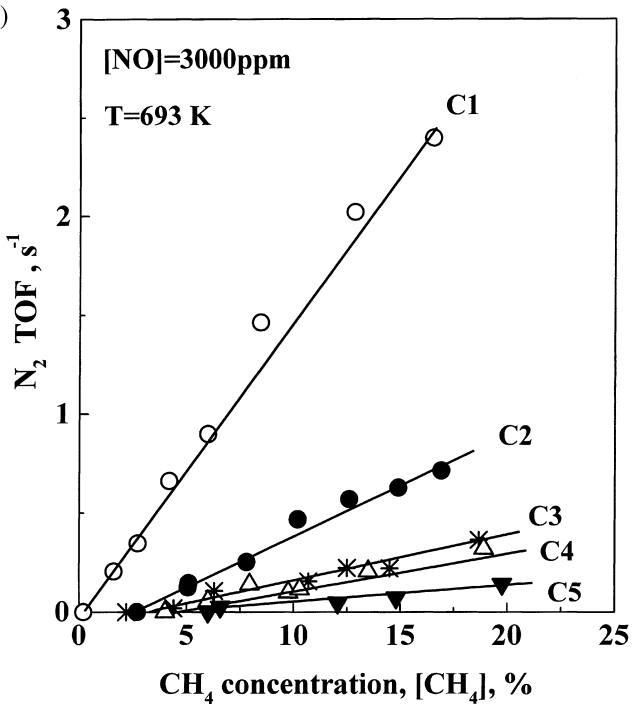

(c)

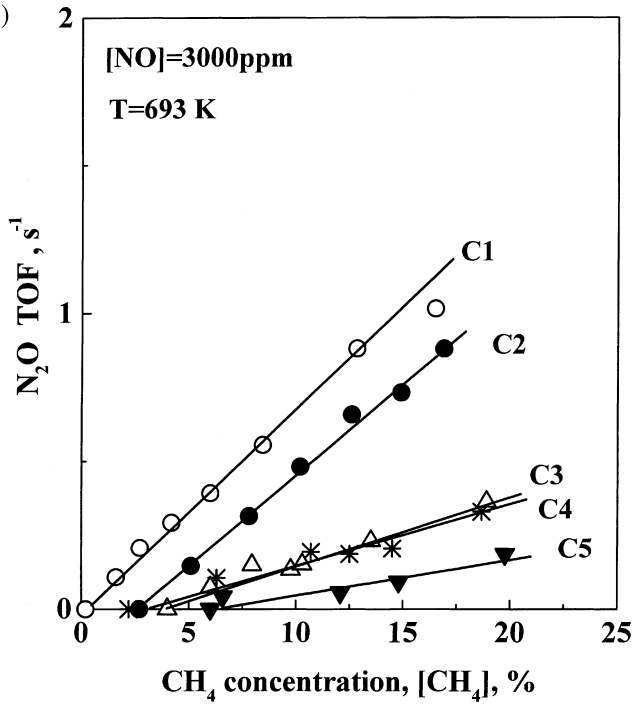

(b)

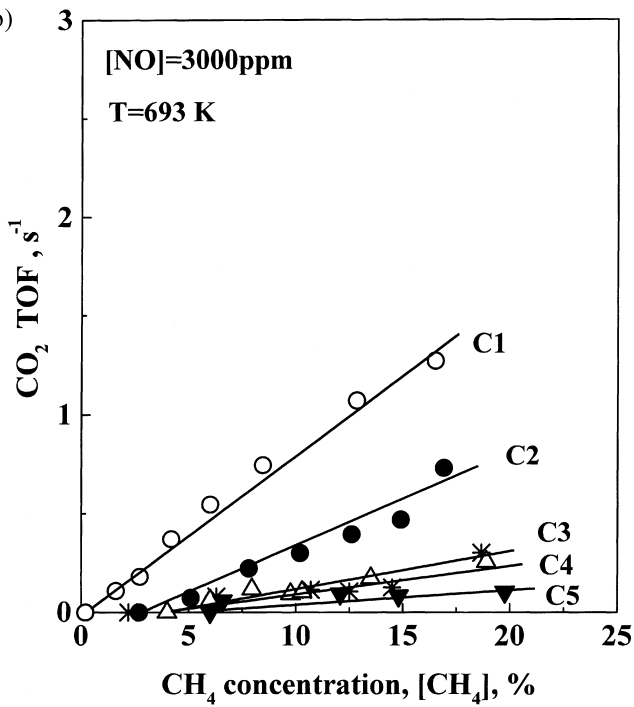

(d)

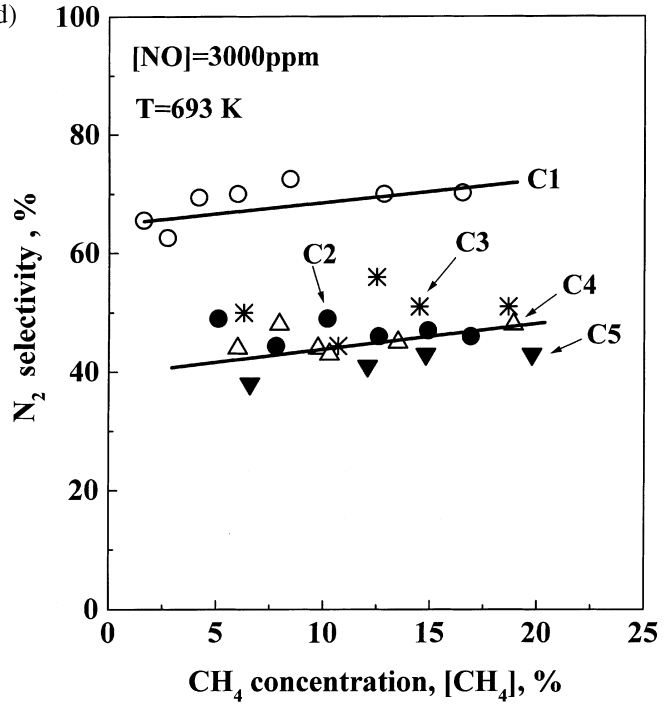

Fig. 3. The effect of $\mathrm{CH}_{4}$ concentration on the TOF rates of (a) $\mathrm{N}_{2}$, (b) $\mathrm{CO}_{2}$, and (c) $\mathrm{N}_{2} \mathrm{O}$ and for (d) $\mathrm{N}_{2}$ selectivity, for catalysts C1-C5 with different $\mathrm{Na}$ content at $693 \mathrm{~K}$ and $[\mathrm{NO}]=3000 \mathrm{ppm}$; concentrations refer to reactor outlet.

higher temperatures and for $100 \%$ NO conversion $\mathrm{N}_{2} \mathrm{O}$ formation is undetectable. The system therefore approaches $100 \%$ selectivity towards $\mathrm{N}_{2}$ at $100 \% \mathrm{NO}$ conversion (Fig. 5(c)). At high temperatures $(>\sim 770 \mathrm{~K})$ and for high $\left[\mathrm{CH}_{4}\right]:[\mathrm{NO}]$ ratios, only very small traces of $\mathrm{NH}_{3}$ were observed.

Fig. 5(a) also shows the production of carbon oxides for $\mathrm{CH}_{4}: \mathrm{NO}=1: 1$ (for other values of this ratio, the $\mathrm{CH}_{4}$ conversion was too small to measure).

Conversions are defined as, $X_{\mathrm{i}}(\%)$, where $\mathrm{i}$ is methane or NO, through the expression:

$X_{\mathrm{i}}(\%)=100\left([\mathrm{i}]_{\text {in }}-[\mathrm{i}]_{\text {out }}\right) /[\mathrm{i}]_{\text {in }}$

where $[\mathrm{i}]_{\text {in }}$ and $[\mathrm{i}]_{\text {out }}$ is the reactor inlet and outlet concentration of $i$, respectively. 

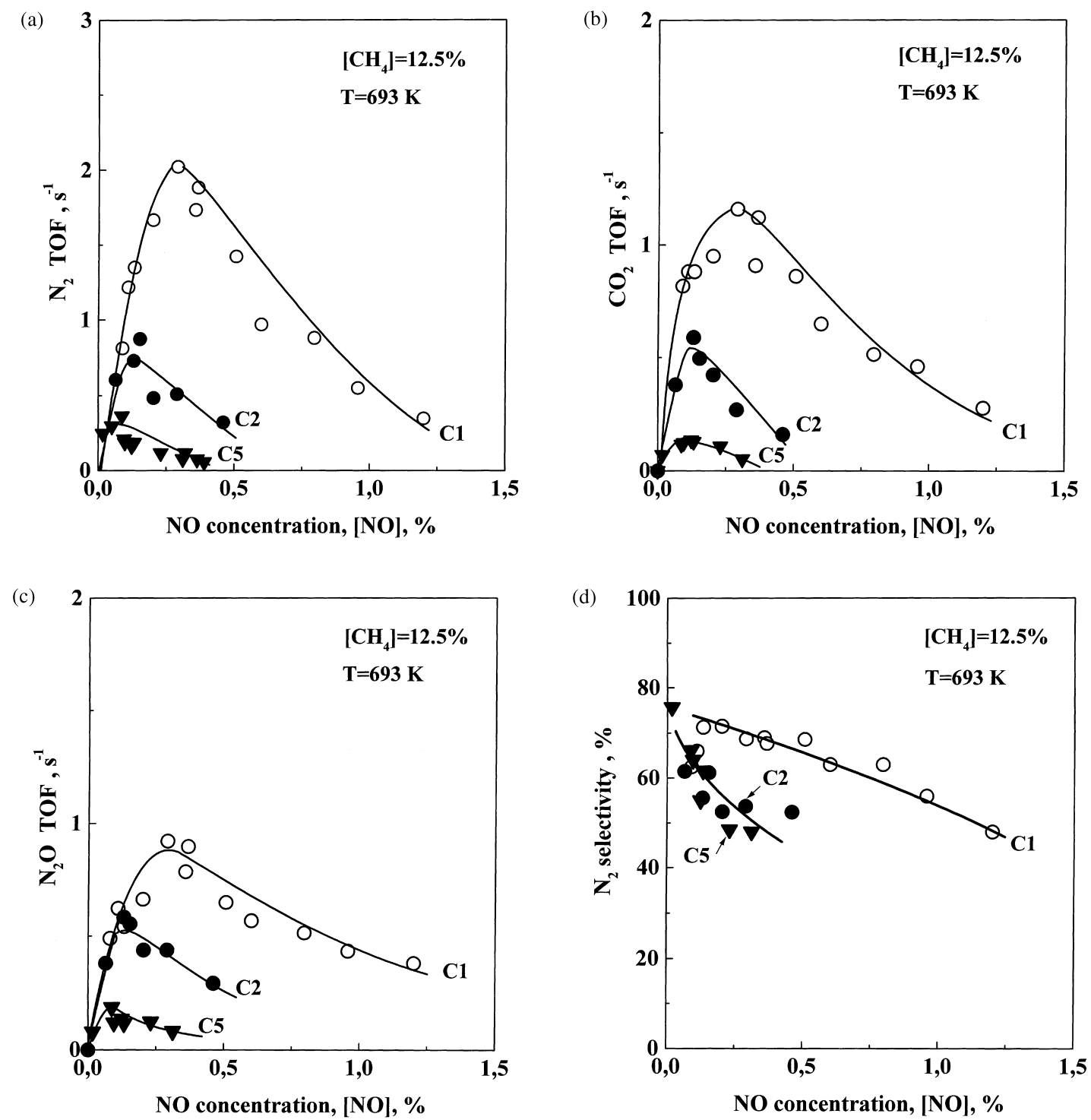

Fig. 4. The effect of $\mathrm{NO}$ concentration on the TOF rates of (a) $\mathrm{N}_{2}$, (b) $\mathrm{CO}_{2}$, and (c) $\mathrm{N}_{2} \mathrm{O}$ and for (d) $\mathrm{N}_{2}$ selectivity, for catalysts C1-C5 with different $\mathrm{Na}$ content at $693 \mathrm{~K}$ and $\left[\mathrm{CH}_{4}\right]=12.5 \%$; concentrations refer to reactor outlet.

\section{Discussion}

\subsection{General}

The present results show that it is possible to use $\mathrm{CH}_{4}$ for the complete removal of $\mathrm{NO}\left(X_{\mathrm{NO}}=100 \%\right)$ at $100 \% \mathrm{~N}_{2}$ selectivity (Fig. 5). However, in agreement with Burch and Ramli [18], we conclude that simultaneous elimination of $\mathrm{NO}$ and methane in exhaust gas under the same conditions is likely to be a difficult optimization problem.

Before discussing the implications of our results, it is useful to recall the chemisorption behaviour of the reactants on the platinum metals in general and on $\mathrm{Pd}$ in particular. Because NO chemisorption is not activated, the resulting surface species can be studied in detail and the surface processes in which they participate are rather well understood. NO adsorption 

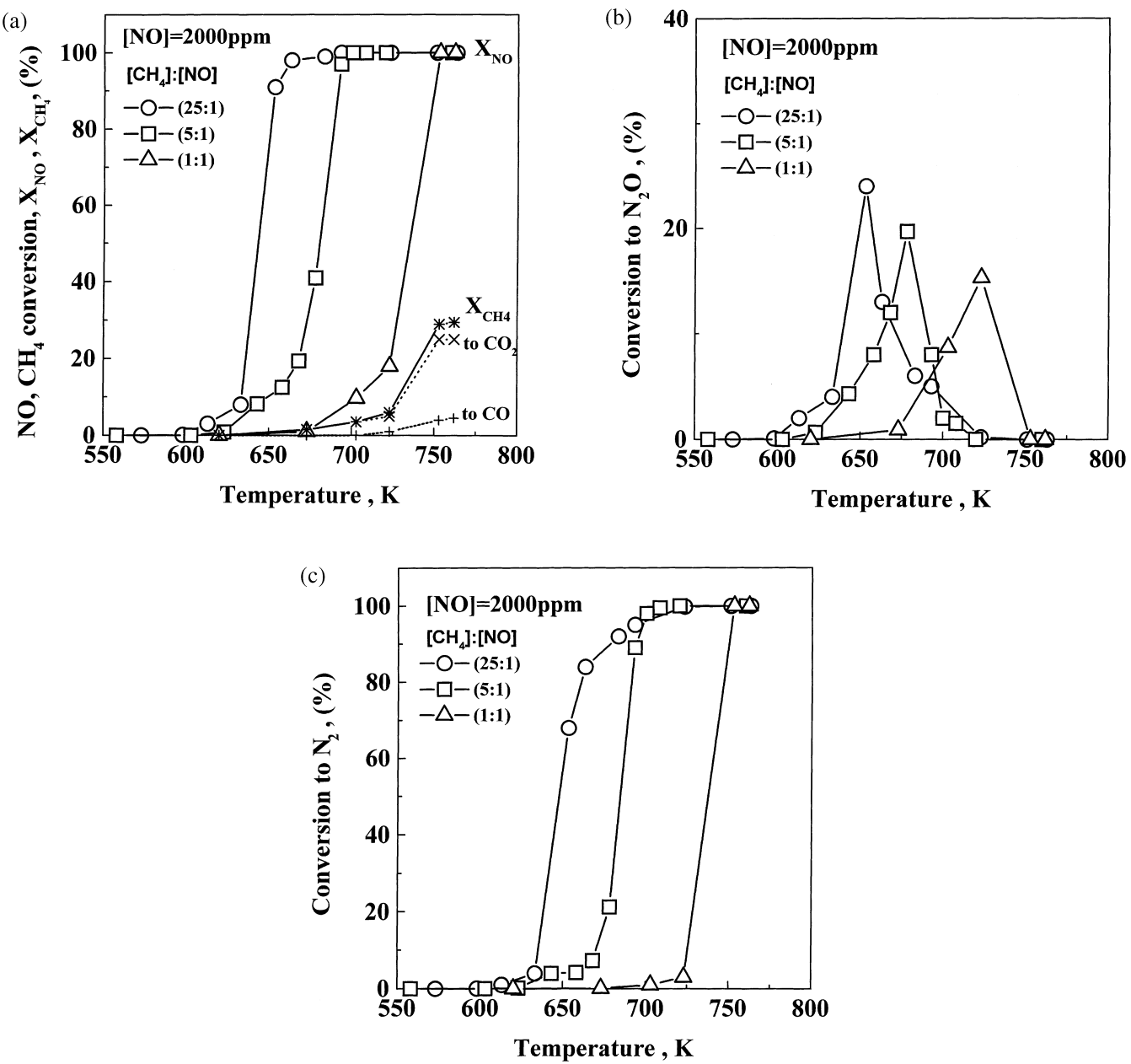

Fig. 5. The conversion of $\mathrm{NO}$ to various products for catalyst $\mathrm{C} 1$ (Na-free) as a function of temperature, at three different $\left[\mathrm{CH}_{4}\right]:[\mathrm{NO}]$ reactant ratios at the inlet of the reactor: (i) $25: 1$ (circles), (ii) $5: 1$ (squares) and (iii) $1: 1$ (triangles), at a constant NO inlet concentration of $2000 \mathrm{ppm}$; total flowrate $F=60 \mathrm{~cm}^{3} \mathrm{~min}^{-1}$; catalyst weight $7.5 \mathrm{mg}$. For the last reactant ratio $(1: 1)$, the conversion of $\mathrm{CH}_{4}$ to various products is also shown in Fig. 5(a).

on Pd has been studied by a very wide range of techniques with samples ranging from single crystals to supported particles of varying dispersion. It is clear that NO dissociation probability is dependent on surface structure, low index planes being less effective than high index planes [28-30]. In line with this, it is found that NO dissociation is more extensive on small Pd particles [31]. In contrast, methane chemisorption is relatively poorly understood: the dynamics are complicated and strongly dependent on surface structure [32], and the products of dissociative chemisorption are unknown. Both trapping- mediated and 'direct' channels contribute [33-35] though it seems clear that at the high gas temperatures and collision frequencies characteristic of conditions in a catalytic reactor, the direct mechanism dominates [35], i.e. methane chemisorbs dissociatively on impact with the metal surface with low probability, even at elevated temperatures. Recent molecular beam/infrared spectroscopy work by Chetsers et al. shows unambiguously that the primary products of methane dissociative chemisorption on the surfaces of platinum group metals are $\mathrm{CH}_{3}(\mathrm{a})+\mathrm{H}(\mathrm{a})$ [36-38]. 
On $\mathrm{Pd}$, in the presence of oxygen adatoms, the dissociative chemisorption probability is reduced further [34] although it is unclear whether this is simply a site-blocking effect or involves longer range electronic interaction [39].

\subsection{Location and chemical state of the 'active' $\mathrm{Na}$}

The catalysts used in this work have been studied in detail by XP and Auger spectroscopy [23]. Although, we could not discriminate between $\mathrm{Na}$ on the metal and on the support, a notoriously difficult problem in catalyst characterisation, it was clear from both the Auger and photoelectron data that there was a monotonic increase in $\mathrm{Na}$ emission with increased $\mathrm{Na}$ loading. Additionally, the behaviour of the spectral intensities showed that there was no significant tendency for the promoter phase to agglomerate with increasing promoter loading. Our view therefore was that the $\mathrm{Na}$ is present on both Pd and support, but that the effects on the catalysis are due to the $\mathrm{Na}$ on the metal phase. The justification for this view, as already noted, was the close correspondence in behaviour between the $\mathrm{Pd} / \mathrm{YSZ}$ catalyst and the EP catalyst, where it is clear that observed effects are due to $\mathrm{Na}$ pumped to the platinum metal film. By analogy with the propene $+\mathrm{NO}$ case, given the correspondence in behaviour between the catalysts used in the present study and the analogous EP system catalysing the $\mathrm{NO}+\mathrm{CH}_{4}$ reaction under $\mathrm{Na}$ modification [26], we infer that the behaviour of our Pd/YSZ catalysts again reflects the effects of $\mathrm{Na}$ in modifying the chemistry of the metal phase.

What is the chemical state of the Na component? XPS results for Na-promoted Pt catalysts transferred directly from reactor to spectrometer after running $\mathrm{NO}+$ hydrocarbon reactions shows the metal carries a mixture of $\mathrm{Na}$ nitrate, carbonate and oxide [21]. It seems likely that the same $\mathrm{Na}$ compounds are present under reaction conditions in this case. As discussed below, it is the $\mathrm{Na}$ ion which acts to enhance NO chemisorption and dissociation, leading to the observed effects on the catalysis.

\subsection{Kinetic behaviour}

In the discussion that follows, formation of nitrogen containing products and, in particular, the dependence of $\mathrm{N}_{2} / \mathrm{N}_{2} \mathrm{O}$ selectivity on reaction variables may be rationalised in terms of the scheme

$\mathrm{NO}(\mathrm{g}) \rightarrow \mathrm{NO}(\mathrm{a}) \quad$ reaction $(1)$

(enhanced by $\mathrm{Na}$ addition)

$\mathrm{NO}(\mathrm{a}) \rightarrow \mathrm{N}(\mathrm{a})+\mathrm{O}(\mathrm{a})$ reaction $(2)$

(enhanced by $\mathrm{Na}$ addition)

$\mathrm{N}(\mathrm{a})+\mathrm{N}(\mathrm{a}) \rightarrow \mathrm{N}_{2}(\mathrm{~g})$ reaction (3)

$\mathrm{N}(\mathrm{a})+\mathrm{NO}(\mathrm{a}) \rightarrow \mathrm{N}_{2} \mathrm{O}(\mathrm{g})$ reaction (4)

While $\mathrm{O}$ (a) reacts with the adsorbed hydrocarbonaceous species resulting from methane dissociative adsorption to yield $\mathrm{CO}_{2}+\mathrm{H}_{2} \mathrm{O}$.

The kinetic behaviour of the Na-free Pd catalyst (Figs. 1 and 2) indicates LH competitive adsorption of the reactants. It is also apparent from these results that the chemisorption of NO is much more pronounced than that of $\mathrm{CH}_{4}$ under all conditions, as might be expected in view of the known properties of the individual reactants, summarised above.

This view is supported by the following observations:

(i) Sharp rate maxima are observed on varying [NO] at fixed $\left[\mathrm{CH}_{4}\right]$, even at very high concentrations of methane (Fig. 1). Correspondingly, no rate maxima are observed on varying $\left[\mathrm{CH}_{4}\right]$ at fixed [NO] (Fig. 2).

(ii) In the first case, the observed maxima occur at very low $[\mathrm{NO}]:\left[\mathrm{CH}_{4}\right]$ ratios, typically $<0.03$, i.e. very high partial pressures of $\mathrm{CH}_{4}$ relative to $\mathrm{NO}$ are necessary in order to achieve a comparable coverage of both reactants on the Pd surface, thus maximising the rate.

(iii) The occurrence of a threshold $\left[\mathrm{CH}_{4}\right]$ value which must be exceeded before detectable reaction (Fig. 2). Below this threshold, we propose that the reaction is self-poisoned by extensive NO chemisorption, and, more crucially, by one of its dissociation products, atomic oxygen. Recall that atomic oxygen is particularly effective in retarding the dissociative chemisorption of methane on Pd [34].

Thus, under our conditions the surface of the Pd particles is covered predominately with $\mathrm{NO}$ and its dissociation products. This gives rise to the observed negative order in $\mathrm{NO}$ for all rates $(\approx-1)$ at sufficiently high [NO], and the positive first order in $\left[\mathrm{CH}_{4}\right]$ under 
all conditions. As discussed below, these adsorption characteristics are give rise to the very different response to $\mathrm{Na}$ promotion of $\mathrm{NO}$ reduction by methane (this work) vs. propene [23].

The effect of temperature is significant from a practical point of view. We find that there exists a wide temperature range, its limits depending on the $\left[\mathrm{CH}_{4}\right]:[\mathrm{NO}]$ ratio, in which the only nitrogen-contained product is $\mathrm{N}_{2}$ (i.e. $\mathrm{S}_{\mathrm{N}_{2}}=100 \%$ ) while at the same time the conversion of NO is $100 \%$ (Fig. 5). This is a consequence of the 'volcano' dependence of the $\mathrm{N}_{2} \mathrm{O}$ production on temperature (Fig. 5(b)), while $\mathrm{N}_{2}$ production increases monotonically until it accounts for the entire conversion of NO (Fig. 5(c)).

Fig. 5(b) illustrates the point that for any given reaction mixture, $\mathrm{N}_{2} \mathrm{O}$ production exhibits a pronounced maximum as a function of temperature. This reflects two opposing effects of increased temperature, namely (i) an initial increase in the rate of reaction (4) as both the rate constant of reaction (4) and the supply of $\mathrm{N}$ (a) rise (ii) eventual quenching of this reaction as NO dissociation becomes effectively complete. This view is confirmed by the dependence of the temperature for maximum $\mathrm{N}_{2} \mathrm{O}$ conversion on the gas composition, also shown in Fig. 5(b). As the mixture becomes richer in NO, higher temperatures are required for complete dissociation of adsorbed NO and the maximum shifts to higher temperature, as observed.

For temperatures above $\sim 770 \mathrm{~K}$, trace amounts of $\mathrm{NH}_{3}$ were formed at high $\left[\mathrm{CH}_{4}\right]:[\mathrm{NO}]$ ratios, in agreement with the findings of Burch and Ramli for $\mathrm{Pd} /$ alumina and $\mathrm{Pd} /$ silica catalysts [18]. We also found that under all conditions used here, the main combustion product was $\mathrm{CO}_{2}$ rather than $\mathrm{CO}$. Carbon monoxide was detected in very small amounts, and only at high temperatures. Its formation rate was always about one order of magnitude less than that of $\mathrm{CO}_{2}$, and Fig. 5(a) shows the 'worst' case where the $\mathrm{CO}$ rate was $\sim 6$ times less than the $\mathrm{CO}_{2}$ rate. Here, our observations differ from those of Burch and Ramli [18] who found that over a wide temperature range $\mathrm{CO}$ was the principal carbon oxide, perhaps reflecting different support effects in the two cases.

\subsection{Mode of action of the Na modifier}

Much has been written about the role of alkalis in modifying the chemistry and catalytic behaviour of metal surfaces. For present purposes, we note the following:

(i) there is no evidence that $\mathrm{Na}$ activates transition metal surfaces for $\mathrm{CH}_{4}$ chemisorption;

(ii) there is very good evidence that $\mathrm{Na}$ activates the $\mathrm{Pt}(111)$ surface towards NO disssociation [27]; (iii) when $\mathrm{Na}$ is supplied to a Pt catalyst by electropumping it strongly promotes the reduction of NO by propene and increases $\mathrm{N}_{2}$ selectivity [21,22]; and

(iv) in quantitative agreement with this, $\mathrm{Na}$ addition to $\mathrm{Pd} / \mathrm{YSZ}$ catalysts also strongly promotes the reduction of $\mathrm{NO}$ by propene, enhancing $\mathrm{N}_{2}$ selectivity and yielding activity enhancements of up to an order of magnitude [23].

Thus, in the case of the NO+propene reaction, both electrochemically promoted (EP) and conventionally promoted by $\mathrm{Na}$, we argue $[23,27]$ that $\mathrm{Na}$ acts by increasing the strength of $\mathrm{NO}$ chemisorption relative to propene, an effect which is accompanied by weakening of the $\mathrm{N}-\mathrm{O}$ bond, thus facilitating NO dissociation on the metal surface. Both theory [40] and experiment [27] show that ionised alkalis co-adsorbed on platinum metal with NO surfaces induce strengthening of the metal- $\mathrm{N}$ bond and weakening of the $\mathrm{N}-\mathrm{O}$ bond by populating the NO $\pi^{*}$ orbital. This occurs because the local electric field due to the alkali ion pulls the NO antibonding orbital below the metal Fermi level [40].

Rate enhancement is therefore due to (i) increased coverage of $\mathrm{NO}$ in the presence of strongly adsorbing propene (ii) triggering of $\mathrm{NO}$ dissociation, which is the reaction-initiating step. The enhancement of NO adsorption (an electronegative adsorbate) and the inhibition of propene adsorption (an electropositive adsorbate) by $\mathrm{Na}$ is the key point.

These effects act to increase both the NO coverage and its degree of dissociation. Once $\mathrm{O}(\mathrm{a})$ is produced it is scavenged by adsorbed hydrocarbonaceous species, accompanied by $\mathrm{N}$ (a) recombination or reaction with $\mathrm{NO}$ (a) to yield $\mathrm{N}_{2}$ and $\mathrm{N}_{2} \mathrm{O}$, respectively. At sufficiently high Na loadings, both the EP and conventional $\mathrm{Pd} / \mathrm{YSZ}$ catalysts exhibit poisoning due to site blocking by Na surface compounds.

In the present case, similar phenomena are at work but the consequences are very different. All the evidence is consistent with the view that dissociative chemisorption of $\mathrm{CH}_{4}$ competes ineffectively with 
NO adsorption and disssociation. Addition of $\mathrm{Na}$ promotes the latter but not the former. Therefore, poisoning by $\mathrm{Na}$ is observed under all conditions due to over-population of the surface with $\mathrm{NO}$ and its dissociation products.

Three findings in particular are consistent with this view:

(i) Competitive adsorption of the NO and methane on the Pd surface is manifest in the LH kinetic behaviour (Figs. 1 and 4): the reaction rates exhibit maxima as a function of $\mathrm{NO}$ concentration. More significantly, these rate maxima shift to lower [NO] as the sodium content of the catalyst is increased (Fig. 4), reflecting an increase in the binding strength of NO relative to methane with increasing $\mathrm{Na} / \mathrm{Pd}$ ratio, i.e. $\mathrm{Na}$ enhances $\mathrm{NO}$ chemisorption vs. methane chemisorption on $\mathrm{Pd}$ catalyst. This is exactly the kind of behaviour one would expect. $\mathrm{Na}$, an electron donor, should enhance the chemisorption of NO (an electron acceptor) and increase its tendency to dissociation. On the other hand, it does not electronically affect the dissociative chemisorption of methane, but does exert a negative influence by site blocking. Therefore, increasing the amount of sodium should decrease the value of $[\mathrm{NO}]$ at which the rate maximum occurs, in accord with observation (Fig. 1).

(ii) $\mathrm{Na}$ always acts to decrease $\mathrm{N}_{2}$ selectivity (Fig. 3(d) and Fig. 4(d)). This may be understood in the following terms. In effect, $\mathrm{Na}$ inhibits the adsorption of $\mathrm{CH}_{4}$ by enhancing the adsorption of NO. The clean-off of $\mathrm{O}$ (a) by adsorbed hydrocarbonaceous species is thereby inhibited, leading to an overall loss of activity towards all products, principally due to poisoning by $\mathrm{O}(\mathrm{a}) . \mathrm{N}_{2} \mathrm{O}$ production is relatively less affected by this process because it is independent of $\mathrm{CH}_{4}$ adsorption (unlike $\mathrm{CO}_{2}$ production) and requires the presence of $\mathrm{NO}$ (a) (unlike $\mathrm{N}_{2}$ production, which is favoured by complete dissociation of NO). Hence, $\mathrm{Na}$ causes $\mathrm{N}_{2}$ selectivity to decrease, but the decrease is essentially independent of $\mathrm{CH}_{4}$ concentration (Fig. 3(d)) due to the inefficient adsorption of the latter. Increased $\mathrm{NO}$ concentration increases $\mathrm{NO}(\mathrm{a})$, hence $\mathrm{N}_{2} \mathrm{O}$ production with decreasing $\mathrm{N}_{2}$ selectivity. Addition of $\mathrm{Na}$ enhances $\mathrm{NO}$ adsorption, as explained above, so that $\mathrm{N}_{2}$ selectivity declines even faster with NO concentration (Fig. 4(d)).

(iii) In regard to activity, Figs. 3 and 4 clearly show that for all loadings $\mathrm{Na}$, induces only poisoning. Again, this reflects the weak interaction of methane with the metal surface, relative to NO. Thus, even at low [NO], the catalyst is predominantly covered by NO. As a result, any further enhancement of the Pd-NO bond strength and NO dissociation probability due to $\mathrm{Na}$ addition results in poisoning. Recall that $\mathrm{O}$ adatoms are particularly effective in inhibiting the dissociative chemisorption of methane on Pd [34]. With alkenes however, due to their much stronger interaction with the metal surface [41], a wide range of conditions exist for which the surface is predominantly covered by hydrocarbon. Na electronically enhances and inhibits the adsorption of $\mathrm{NO}$ and propene, respectively, as explained in detail in Ref. [21], by means of metal-mediated charge transfer to the co-adsorbates. This results in strong promotion of the $\mathrm{NO}+$ propene reaction, as indeed observed. We therefore have a consistent explanation for the response of NO reduction by alkenes and alkanes to $\mathrm{Na}$ modification of platinum-group metal catalysts.

\section{Conclusions}

1. Palladium supported on YSZ can be an effective and very selective catalyst for the reduction of $\mathrm{NO}$ to $\mathrm{N}_{2}$ using $\mathrm{CH}_{4}$ as the reductant. There exists a wide temperature regime ( $\sim 700-770 \mathrm{~K})$ in which $100 \% \mathrm{NO}$ conversion at $100 \% \mathrm{~N}_{2}$ selectivity can be achieved. Nevertheless, complete removal of both reactants under the same conditions seems difficult.

2. Due to the strong chemisorption of NO relative to methane, the reaction tends to self-poisoning by $\mathrm{NO}$ and its dissociation products. As a consequence, initiation requires a high $\left[\mathrm{CH}_{4}\right]:[\mathrm{NO}]$ ratio.

3. Sodium enhances NO chemisorption and dissociation resulting in Na-induced poisoning at all $\mathrm{Na}$ loadings. The poisoning and promotion, respectively, of NO reduction over Pd by methane and by propene can therefore be understood on a consistent basis. 


\section{Acknowledgements}

IVY thanks the Department of Chemical Engineering, University of Patras and ICEHT/FORTH for financial support of this project. This work was also supported in part under grant number GR/K45562 awarded by the UK EPSRC. We thank Johnson Matthey plc for a loan of precious metals.

\section{References}

[1] K.C. Taylor, Catal. Rev.-Sci. Eng. 35 (1993) 457.

[2] J.N. Armor, Appl. Catal. B 1 (1992) 221.

[3] M. Iwamoto, S. Yokoo, K. Sakai, S. Kagawa, J. Chem. Soc. Faraday Trans. 77 (1981) 1629.

[4] S. Sato, Y. Yu-u, H. Yahiro, N. Mizuno, M. Iwamoto, Appl. Catal. A. 70 (1991) L1.

[5] S. Sato, H. Hirabay, H. Yahiro, N. Mizuno, M. Iwamoto, Catal. Lett. 12 (1992) 193.

[6] H. Hamada, Y. Kintachi, M. Sasaki, T. Ito, M. Tabata, Appl. Catal. A. 64 (1990) L1; 70 (1991) L15.

[7] Y. Li, J.N. Armor, Appl. Catal. B 1 (1992) L31.

[8] Y. Li, J.N. Armor, Appl. Catal. B 3 (1993) L1.

[9] Y. Li, J.N. Armor, Appl. Catal. B 2 (1993) 239.

[10] R. Burch, S. Scire, Appl. Catal. B 3 (1994) 295.

[11] C.J. Loughram, D.E. Resasco, Appl. Catal. B 5 (1995) 351; 7 (1995) 113.

[12] M.D. Amiridis, K.L. Roberts, C.J. Pereira, Appl. Catal. B 14 (1997) 203.

[13] A.W. Aylor, L.J. Lobree, J.A. Reimer, A.T. Bell, J. Catal. 170 (1997) 390.

[14] X. Zhang, A.B. Walters, M.A. Vannice, Appl. Catal. B 4 (1994) 237; J. Catal. 146 (1994) 568; Appl. Catal. B 7 (1996) 321.

[15] X. Zhang, A.B. Walters, M.A. Vannice, J. Catal. 155 (1995) 290.

[16] M.A. Vannice, A.B. Walters, X. Zhang, J. Catal. 159 (1996) 119.

[17] S. Subramanian, R.J. Kudla, M.S. Chattha, Ind. Eng. Chem. Res. 31 (1992) 2460.

[18] R. Burch, A. Ramli, Appl. Catal. B 14 (1998) 49.

[19] R. Burch, A. Ramli, Appl. Catal. B 15 (1998) 63.
[20] (a) C.G. Vayenas, S. Bebelis, I.V. Yentekakis, H-G. Lintz, Catal. Today 11 (1992) 303; (b) I.V. Yentekakis, G. Moggridge, C.G. Vayenas, R.M. Lambert, J. Catal. 146 (1994) 292; (c) C.G. Vayenas, I.V. Yentekakis, in: Handbook of Heterogeneous Catalysis, G. Ertl et al. (Eds.), Vol. 13, pp. 1310-1325, VCH, Weinheim/New York, 1997.

[21] I.V. Yentekakis, A. Palermo, N.C. Filkin, M.S. Tikhov, R.M. Lambert, J. Phys. Chem. B 101 (1997) 3759.

[22] I.V. Yentekakis, A. Palermo, N.C. Filkin, M.S. Tikhov, R.M. Lambert, Stud. Surf. Sci. Catal. 116 (1998) 255.

[23] I.V. Yentekakis, R.M. Lambert, M.S. Tikhov, M. Konsolakis, V. Kiousis, J. Catal. 176 (1998) 82.

[24] A. Cowley, in Platinum 1997, Interim Review, Johnson Matthey, London, 1997, p. 18.

[25] C.A. Pliangos, I.V. Yentekakis, V.G. Papadakis, C.G. Vayenas, X.E. Verykios, Appl. Catal. B 14 (1997) 375.

[26] N.C. Filkin, A. Palermo, M.S. Tikhov, R.M. Lambert, in preparation.

[27] I.R. Harkness, R.M. Lambert, J. Chem. Soc. Faraday Transactions 93 (1997) 1425.

[28] S.G. Sugai, H. Watanabe, T. Kioka, H. Miki, K. Kawasaki, Surf. Sci. 259 (1991) 109.

[29] X.P. Xu, P.J. Chen, D.W. Goodman, J. Phys. Chem. 98 (1994) 9242.

[30] S.M. Vesecky, D.R. Rainer, D.W. Goodman, J. Vacuum Sci. Tech. A 14 (1996) 1457.

[31] X.P. Xu, D.W. Goodman, Catal. Letters 24 (1994) 31.

[32] L.Q. Xia, J.R. Engstrom, J. Chem. Phys. 101 (1994) 5329.

[33] M. Valden, J. Pere, N. Xiang, M. Pessa, Chem. Phys. Letters 257 (1996) 289.

[34] M. Valden, J. Pere, M. Hirsimaki, S. Suhonen, M. Pessa, Surf. Sci. 377 (1997) 605.

[35] D.C. Seets, M.C. Wheeler, C.B. Mullins, J. Chem. Phys. 107 (1997) 3986.

[36] D.J. Oakes, M.R. McCoustra, M.A. Chesters, Faraday Discussions 96 (1993) 325.

[37] D.J. Oakes, H.E. Newell, F.J.M. Rutten, M.R. McCoustra, M.A. Chesters, J. Vac. Sci. Technol A 14 (1996) 1439.

[38] H.E. Newell, D.J. Oakes, F.J.M. Rutten, M.R. McCoustra, M.A. Chesters, Faraday Discussions 105 (1996) 193.

[39] M. Valden, N. Xiang, J. Pere, M. Pessa, Appl. Surf. Sci. 99 (1996) 83.

[40] N.D. Lang, S. Holloway, J.K. Norskov, Surf. Sci. 150 (1985) 24.

[41] R. Burch, T.C. Watling, Catal. Letters 43 (1997) 19. 